\title{
Towards Large-Mode-Area fibers fabricated by the full vapor-phase SPCVD process
}

\author{
Alexandre Barnini*a,b, Thierry Robin ${ }^{\mathrm{a}}$, Daniel Caurant ${ }^{\mathrm{b}}$, Thierry Gotter ${ }^{\mathrm{a}}$, Gérard Aka $^{\mathrm{b}}$, Cédric \\ Guyon $^{\mathrm{b}}$, Pascal Guitton ${ }^{\mathrm{a}}$, Ronan Montron ${ }^{\mathrm{a}}$, Arnaud Laurent ${ }^{\mathrm{a}}$

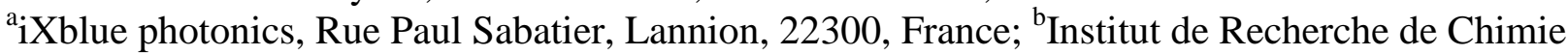 \\ Paris (IRCP), 11 rue Pierre et Marie Curie, Paris, 75005, France.
}

\begin{abstract}
Large-Mode-Area (LMA) fibers are key elements in modern high power fiber lasers operating at $1 \mu \mathrm{m}$. LMA fibers are highly ytterbium-doped and require a fine control of the core refractive index (RI) close to the silica level. These low RI have been achieved with multi-component materials elaborated using a full-vapor phase Surface Plasma Chemical Vapor Deposition (SPCVD) process, enabling the fabrication of large core diameter preforms (up to 4 millimeters). Following the technology demonstration, presented in Photonics West 2017, with results on 10/130 (core-to-clad diameters (in $\mu \mathrm{m}$ ) ratio) fibers, this paper aims to present updated results obtained for double-clad 11/130, 20/130 and 20/400 LMA fibers, with numerical apertures at, respectively, 0.08 and 0.065 . The study is based on aluminosilicate core material co-doped either with fluorine or phosphorus to achieve optimal radial RI tailoring. The fiber produced exhibit low background losses $(<20 \mathrm{~dB} / \mathrm{km}$ at $1100 \mathrm{~nm})$ and high power conversion efficiencies, up to $74 \%$ for output powers of $100 \mathrm{~W}$ limited by our test setup. The Gaussian beam quality has been evaluated using the $\mathrm{M}^{2}$ measurement. Photodarkening behavior will be discussed for both fluorine and phosphorus-doped aluminosilicate materials and particularly the use of cerium as codopant. The SPCVD technology can indeed be used for the production of Yb-doped LMA fibers. Current development is now focused on other rare-earth doped fibers.
\end{abstract}

Keywords: Rare earth-doped fiber, ytterbium, optical amplifier, laser, aluminosilicate fibers, large-mode-area fibers and photodarkening.

*alexandre.barnini@alumni.chimie-paristech.fr; phone +33687138723; www.ixblue.com and www.ircp.cnrs.fr

\section{INTRODUCTION}

Since the first demonstration of a laser emission in 1960 by T. Maiman ${ }^{1}$, lasers represent a major lever of the scientific progress in the photonic world. They enabled the rise of new technolo447 2802gical applications in various fields: materials cutting ${ }^{2}$ and welding, medicine ${ }^{3}$ and defense ${ }^{4}$. Fiber laser technologies have been first put aside by intense activities on crystal or gas lasers. After the fabrication of a first low-attenuation neodymium-doped-silica optical fiber core and its use as a laser cavity in the nineties ${ }^{5}$, research and development on fiber lasers have intensively grown. The large ratio of surface-to-active volume of optical fibers led to excellent heat dissipation ${ }^{6}$ and a good spatial distribution of the signal, resulting in nearly Gaussian beams and higher stability ${ }^{7}$. Ytterbium-doped silica with double-clad design are currently widely used for high power applications. Silica is of great interest as a host for ytterbium ions (and more generally for rare earth (RE) ions), because it leads to a broadening of the RE ion emission and absorption spectra compared to the similar crystal host, and consequently enables a more efficient optical pumping ${ }^{8}$ (at around 915 or $976 \mathrm{~nm}$ in the case of ytterbium-doped optical fiber cores). Nowadays, tendency is to continuously increase output powers. When the power extracted from the fiber increases, deleterious non-linear effects are observed. In order to push their appearance threshold back, smaller lengths of fibers are used, and therefore core diameters are increased to lower the optical density. Finally, the refractive index (RI) of the core is decreased close to the clad RI in order to keep an almost single mode signal. These high power-tailored optical fibers are commonly named as large-mode-area (LMA) fibers. 
In a previous paper ${ }^{9}$, we have presented an innovative process named Surface Plasma Chemical Vapor Deposition (SPCVD) and we have suited it to the fabrication of fibers with $10 \mu \mathrm{m}$ core diameters and compositions $\left(\mathrm{SiO}_{2}-\mathrm{Al}_{2} \mathrm{O}_{3}-\right.$ $\mathrm{Yb}_{2} \mathrm{O}_{3}-\mathrm{F}$ ) that were not accessible with the standard MCVD process, while precisely controlling the dopant incorporation both radially and between consecutive preforms. In this paper, we present our latest results on $11 \mu \mathrm{m}$ core diameter fibers

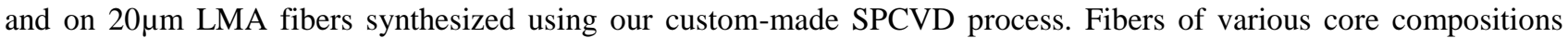
$\left(\mathrm{SiO}_{2}-\mathrm{Al}_{2} \mathrm{O}_{3}-\mathrm{Yb}_{2} \mathrm{O}_{3}-\mathrm{F}\right.$ and $\left.\mathrm{SiO}_{2}-\mathrm{Al}_{2} \mathrm{O}_{3}-\mathrm{P}_{2} \mathrm{O}_{5}-\mathrm{Yb}_{2} \mathrm{O}_{3}\right)$ are studied regarding their attenuation, their power conversion efficiency and their resistance to photodarkening.

\section{PREFORM FABRICATION}

\subsection{Presentation of the SPCVD process}

First described by Pavy et al. in $1986^{10}$, the SPCVD process was used for the production of telecommunication single mode fibers. The technology is based on a low-pressure microwave $(2.45 \mathrm{GHz})$ plasma used to dissociate a mixture of chloride, Freon gases and oxygen, in order to generate oxidation reactions at the inner surface of a synthetic silica tube. The tube is placed at the center of a tubular furnace heated at about $1100^{\circ} \mathrm{C}$ in order to get a vitrified deposit. By positioning the silica substrate tube under vacuum conditions, the ignition of a microwave discharge is possible. The microwaves propagate along the inner surface of the dielectric substrate tube thus supporting the plasma column: the plasma is self-sustained. But the amplitude of the electromagnetic field decreases from the point of application of the plasma to the end of the column, and so does the concentration of electrons. The plasma column subsists only above a critical concentration of $4.31 \times 10^{11}$ electrons. $\mathrm{cm}^{-3},{ }^{11}$. The reagents used in this paper for the deposits are: $\mathrm{SiCl}_{4}, \mathrm{AlCl}_{3}$, $\mathrm{YbCl}_{3}, \mathrm{P}_{2} \mathrm{O}_{5}, \mathrm{CeCl}_{3}$ and $\mathrm{C}_{2} \mathrm{~F}_{6}$. The deposit takes place on the first centimeters of the plasma column (Fig. 1). Since the microwave power applied dictates the length of the plasma column, by modulating this power, the deposit area can be shifted forward and backward in order to get a total length of deposit of several hundred millimeters. The plasma scanning frequency used in our experiments is $0.5 \mathrm{~Hz}$ and we successfully synthesized a vitrified deposition of $400 \mathrm{~mm}$ length in a 16x20mm (IDxOD) tube, where each glassy layer deposited has a thickness of several tenths of nanometers.

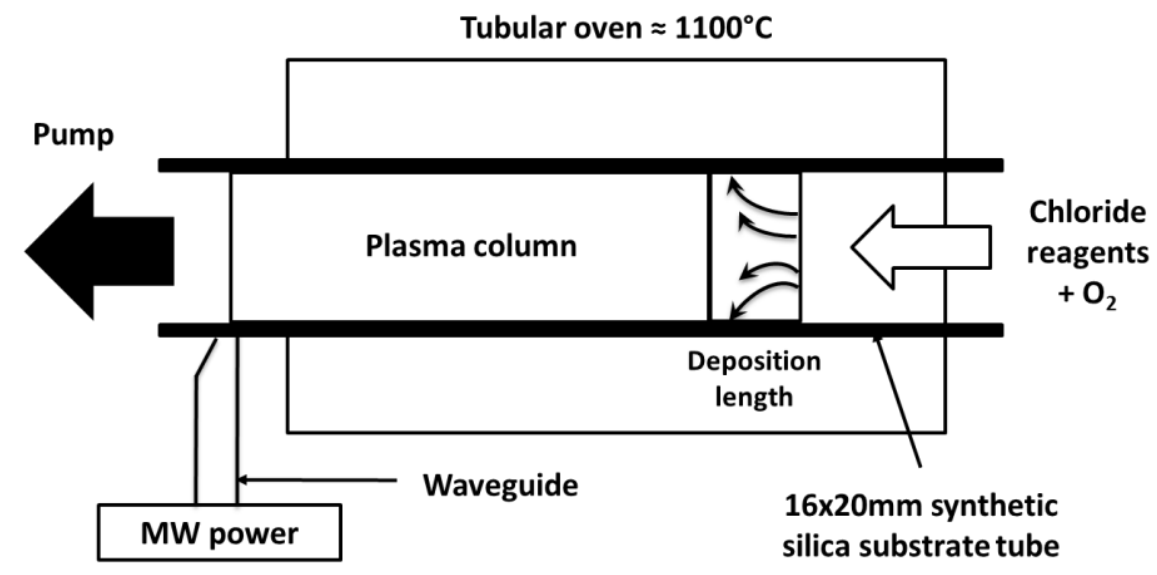

Figure 1: Schematic principle of the SPCVD process

\subsection{Evaporation of aluminum and rare earth chlorides}

We use $5 \mathrm{~N}$ purity anhydrous aluminum chloride $\left(\mathrm{AlCl}_{3}\right)$ as a precursor for aluminum, and the reagent is placed into a silica reactor. By heating the precursor in an oven at $100^{\circ} \mathrm{C}$ at around $1 \mathrm{mbar}$, the vapors are generated and carried out to the plasma reaction area by way of an inert gas. A high temperature mass flow controller is located in the oven in order to properly control the amount of aluminum delivered to the reaction zone to ensure repeatable layer composition. 
We use $4 \mathrm{~N}$ purity anhydrous ytterbium and anhydrous cerium chlorides as precursors for ytterbium and cerium respectively. The reagents are placed into two quartz reactors located close to the reaction zone (Fig.2). The temperature of each reactor is controlled independently. By heating the precursors at around $800^{\circ} \mathrm{C}$ and $1 \mathrm{mbar}$, the vapors are generated and carried out to the plasma reaction area by way of an inert gas. A great care has been taken to design the reactor such as to prevent any gas (and especially oxygen) to come into contact with the rare earth chloride powders during the deposition time. A simplified set-up (with only the evaporation of ytterbium chloride) is presented in Fig. 2.

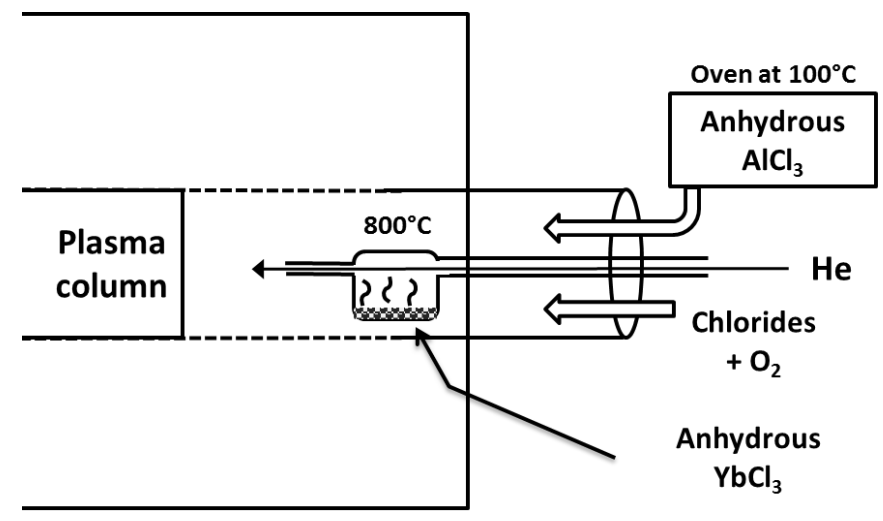

Figure 2: Evaporation of anhydrous $\mathrm{AlCl}_{3}$ and $\mathrm{YbCl}_{3}$

\section{PREFORM AND FIBER CHARACTERIZATIONS}

\subsection{Refractive index and chemical composition}

The refractive index profiles (RIP) of the cores have been obtained using a PK2600 (Photon Kinetics) preform analyzer, scanning the preform both radially and longitudinally with a He-Ne light beam at $633 \mathrm{~nm}$.

The chemical composition of the cores has been analyzed using an electron microprobe Cameca SX100 (15kV, 50nA), at the CAMPARIS department of the Pierre et Marie Curie University. The analysis has been made on slices of the preform, previously polished and metallized.

\subsection{Attenuation}

The attenuations of the cores presented in this work have been measured at 1310nm using the well-known Optical Time Domain Reflectometry method.

\subsection{Power conversion efficiency and $\mathrm{M}^{2}$ coefficient}

In order to test our Yb-doped active cores synthesized by the SPCVD process, we used the laser cavity set-up presented in Fig. 3. Up to six $30 \mathrm{~W}$ multimode pump diodes were used to inject power at $915 \mathrm{~nm}$ in the double-clad $\mathrm{Yb}$-doped fiber under test. The power of each multimode pump diode is first combined in a passive double-clad fiber through a pump combiner (LasFiberio). The $\mathrm{Yb}$-doped fiber under test is spliced between two fiber Bragg gratings, $\mathrm{R}_{\max }$ and $\mathrm{R}_{\min }$ (made at $i X$ blue photonics). $\mathrm{R}_{\max }$ reflects more than $99 \%$ of the laser signal at $1064 \mathrm{~nm}$ (and delivers $98.5 \%$ of the pump signal at $915 \mathrm{~nm}$ ) whereas $R_{\min }$ reflects around $9 \%$ of this signal, which enables to create a continuously-pumped laser cavity. The power conversion efficiency (PCE) is defined as the ratio between the output power at $1064 \mathrm{~nm}$ and the absorbed pump power at $915 \mathrm{~nm}$.

For the evaluation of the laser beam quality, the $\mathrm{M}^{2}$ parameter is measured and enables to quantify the deviation of the emitted beam from a perfect Gaussian beam $\left(\mathrm{M}^{2}=1.0\right)$. The emitted beam at the output of the laser cavity is then focused on a beam analyzer (Ophir). 


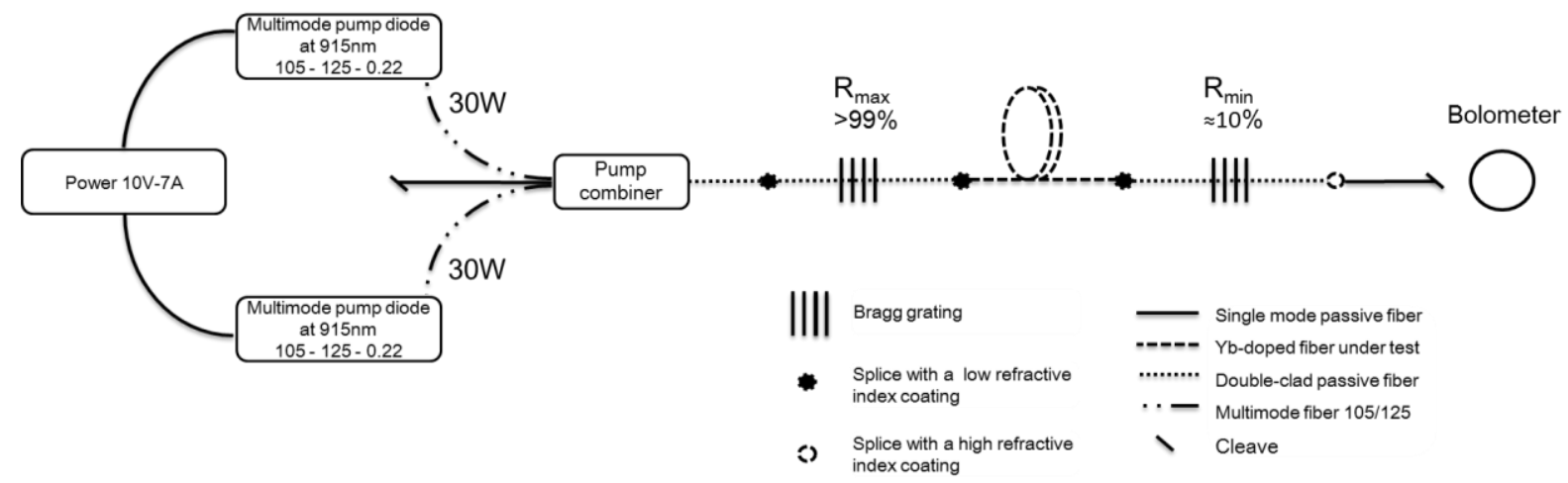

Figure 3: Set-up for the evaluation of power conversion efficiency of Yb-doped fibers

\subsection{Evaluation of photodarkening phenomenon}

Photodarkening (PD) is a well-known detrimental effect in aluminosilicate ytterbium-doped optical fiber ${ }^{12}$ impeding fiber laser lifetime. It can be appreciatively reduced by co-doping with cerium ${ }^{13}$ in aluminosilicate fibers or using a

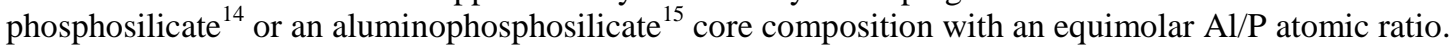

We measured PD using a classic setup by core-pumping a short length of fiber at 976nm and measuring the fiber transmission at 635nm (Fig. 4). Indeed, it is known that colored-centers appear due to the pump signal and lead to strong absorption bands below $700 \mathrm{~nm}^{16}$.

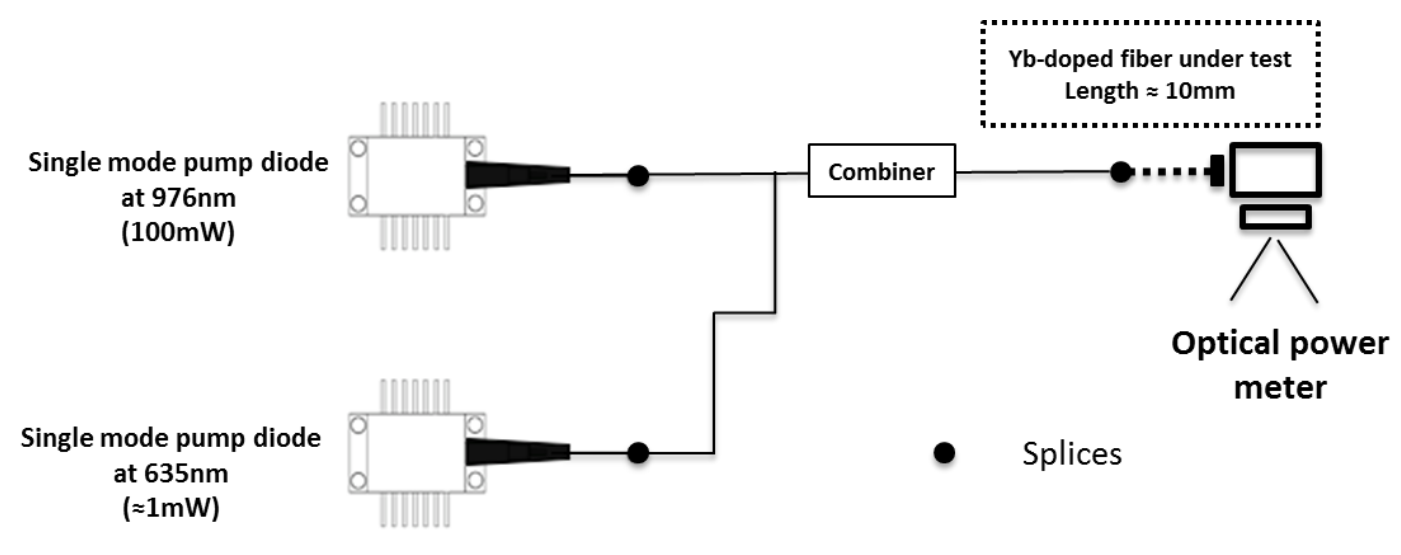

Figure 4: Set-up for the evaluation of the photodarkening

\section{RESULTS}

The characterizations and results on our SPCVD-made fibers are presented in two parts. The first one focuses on fibers with $11 \mu \mathrm{m}$ core diameter and $130 \mu \mathrm{m}$ clad diameter, and the second one on larger core diameter fibers $(20 \mu \mathrm{m})$. 


\subsection{Characterizations of the 11/130 fibers}

Following the work of our previous paper ${ }^{9}$, the results on two fibers are presented here. The compositions of the cores are different: the first one, $\mathrm{SiO}_{2}-\mathrm{Al}_{2} \mathrm{O}_{3}-\mathrm{Yb}_{2} \mathrm{O}_{3}-\mathrm{Ce}_{2} \mathrm{O}_{3}-\mathrm{F}$, is called AlFYbCe and the second one, $\mathrm{SiO}_{2}-\mathrm{Al}_{2} \mathrm{O}_{3}-\mathrm{P}_{2} \mathrm{O}_{5}-\mathrm{Yb}_{2} \mathrm{O}_{3}$, not studied previously, is called AlPYb. In order to successfully incorporate both aluminum and phosphorus with a vapor

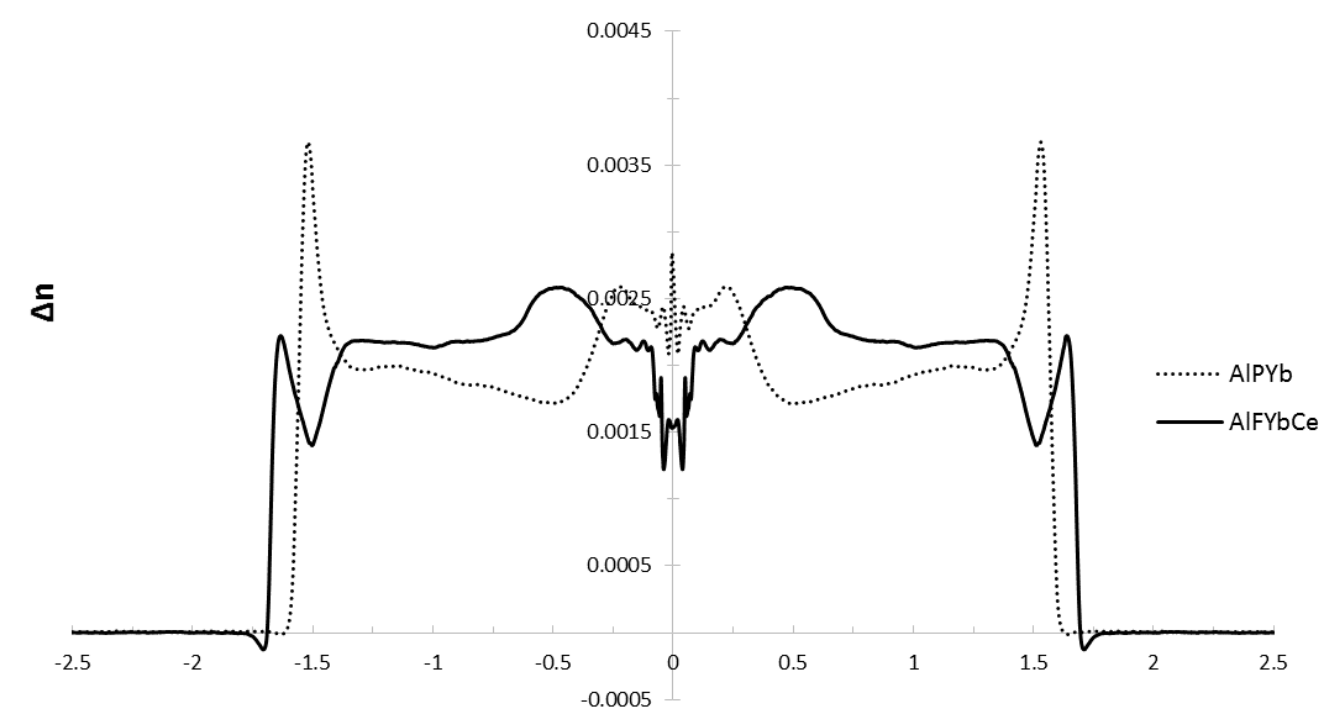

Radius (mm)

Figure 5: RIP of AlFYbCe (full line) and AlPYb (dashed line) preform cores

phase process, one has to be careful not to mix gaseous $\mathrm{AlCl}_{3}$ and $\mathrm{POCl}_{3}$, because they react together to create an unwanted complex ${ }^{17}$, which condensates before the reaction zone.

\subsubsection{Preform characterizations}

Figure 5 shows the RIP of the AlPYb and AlFYbCe cores made by the full vapor phase SPCVD. Both exhibit $>3 \mathrm{~mm}$ diameter cores with a slight inhomogeneity both on the sides and at the center $(\approx 1 \mathrm{~mm})$ of the profiles. The mean refractive indexes of the AlFYbCe and AlPYb cores are respectively 2.30 and $2.20 \times 10^{-3}$. The average measured composition of the dopants in both cores is given in table 1. Aluminum and ytterbium concentrations are almost the same in the two cores.

\begin{tabular}{|c|c|c|c|c|c|}
\hline \% molar atomic & $\mathrm{Al}$ & $\mathrm{Yb}$ & $\mathrm{F}$ & $\mathrm{P}$ & $\mathrm{Ce}$ \\
\hline $\mathrm{AlFYbCe}$ & 1.25 & 0.11 & 1.0 & 0 & 0.02 \\
\hline $\mathrm{AlPYb}$ & 1.33 & 0.11 & 0 & 1.28 & 0 \\
\hline
\end{tabular}

Table 1: Composition of the AlFYbCe and AlPYb cores

Two octagonal double-clad fibers with an 11/130 core-to-clad ratio and a core numerical aperture of 0.08 have been drawn from those preforms and are characterized in the following sections. The octagonal geometry was chosen so that the fibers could be easily tested with on the shelf components.

\subsubsection{Fiber characterizations}

In a first step, the fibers have been characterized in terms of core attenuation at $1310 \mathrm{~nm}$. The results are presented in table 2, where the drawing tension is noticed.

\begin{tabular}{|l|c|c|c|}
\hline & Numerical aperture & Drawing tension $(\mathrm{g})$ & $\begin{array}{c}\text { Attenuation at 1310nm } \\
(\mathrm{dB} / \mathrm{km})\end{array}$ \\
\hline
\end{tabular}




\begin{tabular}{|c|c|c|c|}
\hline AlFYbCe & 0.085 & 82 & 25.3 \\
\hline AlPYb & 0.081 & 101 & 64.9 \\
\hline
\end{tabular}

Table 2: Attenuation at $1310 \mathrm{~nm}$ of the AlFYbCe and AlPYb cores

The drawing tension of our AlFYbCe fibers has been optimized in order to lower the attenuation at 1310nm down to $25.3 \mathrm{~dB} / \mathrm{km}$, which is currently the lowest obtained for this core composition. The AlPYb core composition has been developed more recently, therefore the drawing tension is not optimized, but led to a $64.9 \mathrm{~dB} / \mathrm{km}$ attenuation at $1310 \mathrm{~nm}$ which is compatible with the production of double clad fibers. The numerical aperture of both fibers is close to 0.08 . RI measurement using our InterFiber Analysis IFA-100 optical fiber analyzer on these fibers did not show significant modification induced by the drawing phase indicating that no major diffusion mechanism takes place during the drawing process.

AlFYbCe and AlPYb fibers exhibit respectively a multimode pump absorption of 1.35 and $1.31 \mathrm{~dB} / \mathrm{m}$ at $915 \mathrm{~nm}$. The PCE, corresponding to the ratio of the cavity output power at $1064 \mathrm{~nm}$ versus the absorbed pump power at $915 \mathrm{~nm}$, is given in Fig. 6. It was measured at $78 \%$ up to $44 \mathrm{~W}$ of pump power for a $7.5 \mathrm{~m}$ long piece of AlFYbCe fiber, and at $71.3 \%$ up to $28 \mathrm{~W}$ for a $8 \mathrm{~m}$ long piece of AlPYb fiber. These results are in line with the state of the art of similar core compositions made by other processes ${ }^{18}$. Moreover, the $\mathrm{M}^{2}$ parameter has been measured at 1.06 for the AlFYbCe fiber and at 1.20 for the AlPYb fiber, at an output power around $3.8 \mathrm{~W}$.

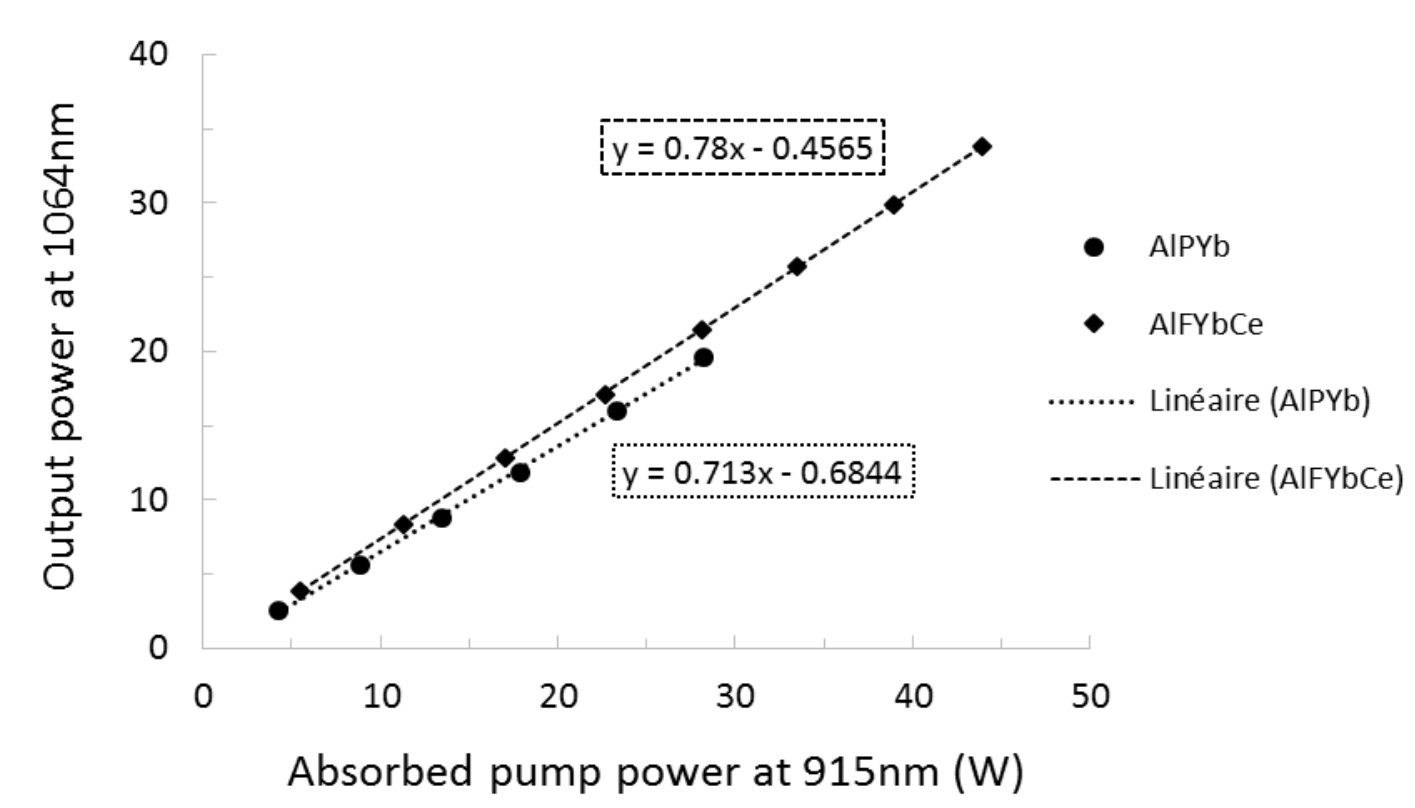

Figure 6: PCE of 11/130 double clad AlFYbCe (circular dots) and AlPYb (rectangular dots) fibers

The photodarkening phenomenon has been evaluated by core-pumping at $976 \mathrm{~nm}$ around $10 \mathrm{~mm}$ long of each fibers during $1000 \mathrm{~min}$, and the results are given in Fig. 7. We observe that the attenuation penalty at $635 \mathrm{~nm}$ of each core remains low (only $\approx 26 \mathrm{~dB} / \mathrm{m}$ ), compared to the SPCVD-made AlFYb fiber without cerium, whose attenuation keeps increasing. This result shows the major role of cerium to mitigate photodarkening in AlFYb cores compositions, but also the appreciated property of $\mathrm{AlPYb}$ cores compositions with an equimolar $\mathrm{Al} / \mathrm{P}$ ratio to mitigate photodarkening without the need to incorporate cerium ${ }^{15}$.

Finally, the 11/130 Yb-double clad fibers made by SPCVD exhibit good lasing properties with high PCE: 71.3 and $78.0 \%$ for AlPYb and AlFYbCe fibers respectively. The $\mathrm{M}^{2}$ parameters are close to 1.0, especially for the AlFYbCe fiber $\left(\mathrm{M}^{2}=1.06\right)$. Moreover, both fibers are photodarkening-resistant even though a small content of cerium is needed in the composition of AlFYb cores. We believe that the lasing properties can be improved by adding particularly a small 
content of germanium to the composition in order to reduce the attenuation of our rare earth-doped cores, as already demonstrated in the litterature ${ }^{19}$.

The next section of this paper focus on fiber characterizations of AlFYbCe fibers with $20 \mu \mathrm{m}$ core diameters.

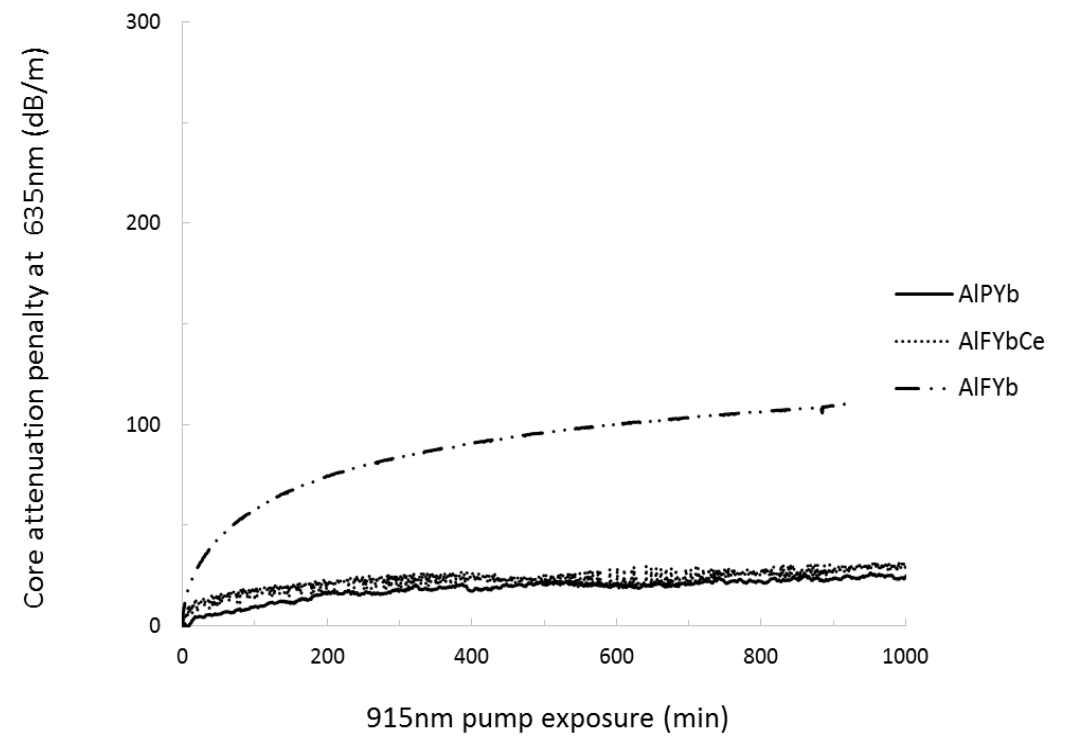

Figure 7: Photodarkening measurements on 11/130 AlFYb (dashed line), AlFYbCe (dots) and $\mathrm{AlPYb}$ (full line) fibers

\subsection{Characterizations of LMA fibers with $20 \mu \mathrm{m}$ core diameter}

We present here the characterizations of two LMA fibers with $20 \mu \mathrm{m}$ core diameter. Both fibers have the same core composition: $\mathrm{SiO}_{2}-\mathrm{Al}_{2} \mathrm{O}_{3}-\mathrm{Yb}_{2} \mathrm{O}_{3}-\mathrm{Ce}_{2} \mathrm{O}_{3}-\mathrm{F}$, but one has a $130 \mu \mathrm{m}$ clad diameter and is called 20/130, whereas the other one has a $400 \mu \mathrm{m}$ clad diameter and is called 20/400.

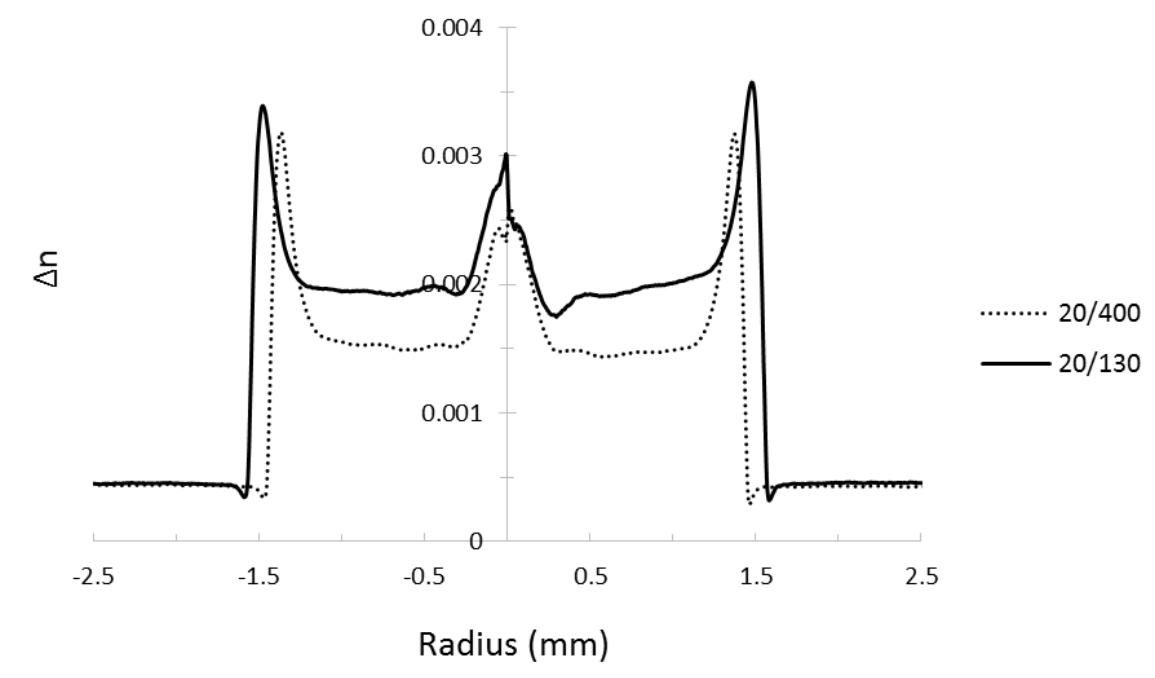

Figure 8: RIP of AlFYbCe 20/130 (full line) and 20/400 (dashed line) preform cores 


\subsubsection{Preform characterizations}

Figure 8 shows the RIP of the 20/130 and 20/400 preform cores made by the SPCVD process. As for previous RIP (Fig. 5 ), both exhibit $>3 \mathrm{~mm}$ diameter cores with a slight inhomogeneity on the sides but with a narrower raising of the refractive index at the center of the profiles $(\approx 0.5 \mathrm{~mm})$. The average refractive indexes of the 20/130 and 20/400 cores are respectively 2.10 and $1.6 \times 10^{-3}$. The average content of the dopants in both cores is given in table 3 .

\begin{tabular}{|c|c|c|c|c|}
\hline \% molar atomic & $\mathrm{Al}$ & $\mathrm{Yb}$ & $\mathrm{F}$ & $\mathrm{Ce}$ \\
\hline $20 / 130$ & 1.17 & 0.10 & 0.98 & 0.030 \\
\hline $20 / 400$ & 0.94 & 0.08 & 0.95 & 0.026 \\
\hline
\end{tabular}

Table 3: Composition of the 20/130 and 20/400 cores

Two octagonal double-clad fibers with a 20/130 and a 20/400 core-to-clad ratio and a core numerical aperture of 0.08 and 0.067 respectively have been drawn from those preforms and are characterized in the following sections.

\subsubsection{Fiber characterizations}

The data given in table 4 present the characteristics of each fiber, where the drawing tension is pointed out. Because of the low NA of the $20 / 400$ fiber, the attenuation at $1310 \mathrm{~nm}$ couldn't be evaluated using the OTDR due to excessive bending losses.

\begin{tabular}{|c|c|c|c|c|}
\hline & Numerical aperture & Drawing tension $(\mathrm{g})$ & $\begin{array}{c}\text { Attenuation at 1310nm } \\
(\mathrm{dB} / \mathrm{km})\end{array}$ & $\begin{array}{c}\text { Background } \\
\text { multimode loss at } \\
1100 \mathrm{~nm}(\mathrm{~dB} / \mathrm{km})\end{array}$ \\
\hline $20 / 130$ & 0.08 & 65 & 63.0 & 17.8 \\
\hline $20 / 400$ & 0.067 & 139 & Non-measured & 4.5 \\
\hline
\end{tabular}

Table 4: Characteristics of the 20/130 and 20/400 cores

As previously mentioned, RI measurement on these fibers did not show any significant modification induced by the drawing process from the preform-measured RI.

$20 / 130$ and 20/400 cores exhibit respectively a multimode absorption of 3.31 and $0.37 \mathrm{~dB} / \mathrm{m}$ at $915 \mathrm{~nm}$, therefore $3.9 \mathrm{~m}$ long piece of 20/130 fiber and 27.0m long piece of 20/400 fiber have been used to evaluate the PCE, whose results are presented in Fig. 9.

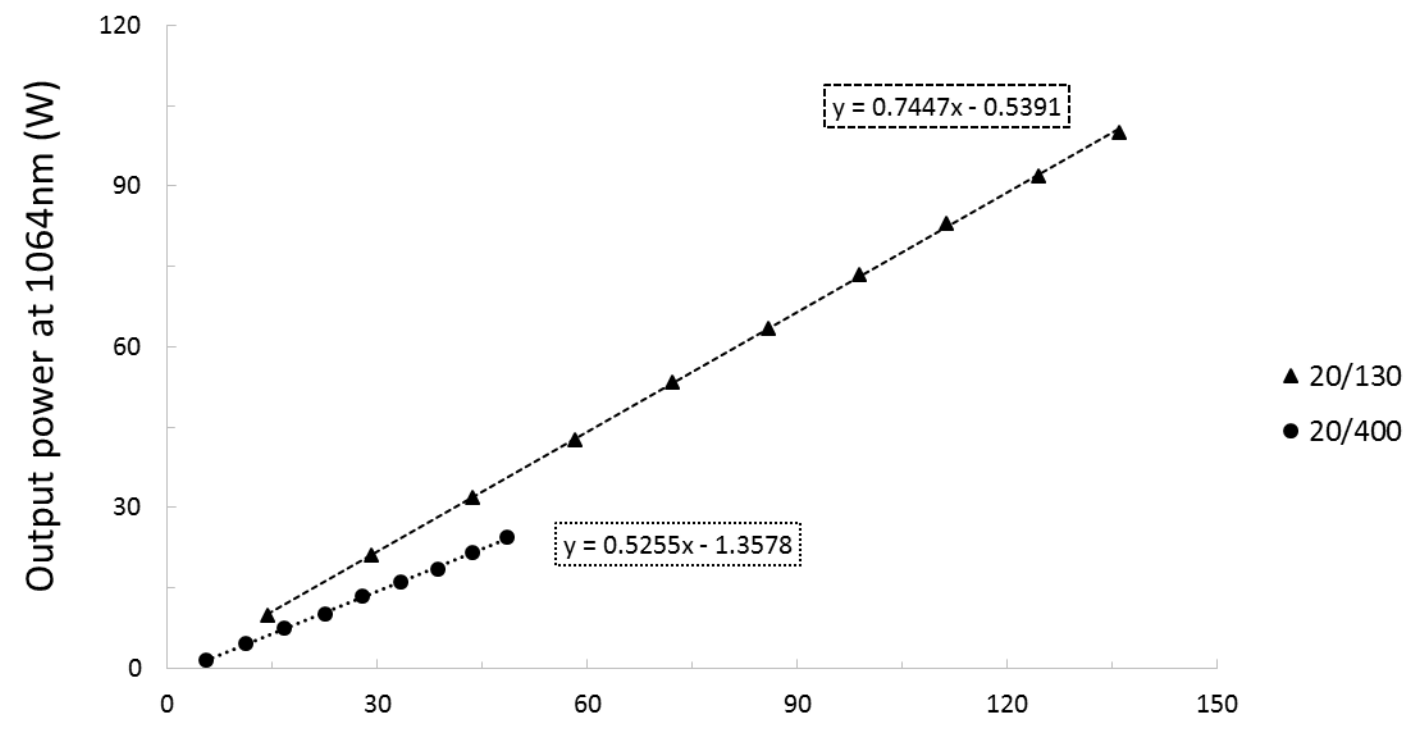

Absorbed pump power at $915 \mathrm{~nm}(\mathrm{~W})$

Figure 9: PCE of AlFYbCe 20/130 (triangular dots) and 20/400 (circular dots) fibers 
The maximum injected pump power for the 20/130 fiber is $136 \mathrm{~W}$, at which was obtained an output power at $1064 \mathrm{~nm}$ of $100 \mathrm{~W}$ and led to a PCE of $74.5 \%$. The injected power is only limited by the number of available pump diodes, and it would be very interesting to test the fiber at higher powers. The $\mathrm{M}^{2}$ parameter has been measured at 1.53 for this fiber at an output power of 10W. On the other hand, the injected pump power for the 20/400 fiber was limited to only $48 \mathrm{~W}$, and we obtained an output power of $24.5 \mathrm{~W}$. The measured PCE is around 53\%, and the $\mathrm{M}^{2}$ parameter has been measured at 1.03 for this fiber at an output power of $10 \mathrm{~W}$.

We believe that the PCE on this first version of an SPCVD-made 20/400 LMA fiber will be improved through splice process optimization. We did observe significant heating at the splice locations in our set-up and splice loss measurements were performed and confirmed unusually high signal losses. We are confident that the core quality is not the cause of the low PCE because equivalent composition cores yielded good lasing properties when used as 11/130 geometry type fibers. Furthermore, we measured some equivalent 20/400 fibers available on the market with our PCE test set-up and found similar values. Process improvement on splicing $400 \mu \mathrm{m}$ diameter fibers is ongoing, and updated results will be presented at the conference. Conversely, fibers with a $130 \mu \mathrm{m}$ clad diameter are regularly spliced and well handled, which can explain the high PCE obtained with the 20/130 fiber for such powers.

Furthermore, the photodarkening has not been evaluated yet on 20/130 and 20/400 fibers, but we do not expect any different behavior from the 11/130 AlFYbCe fiber, because the core composition is similar.

\section{CONCLUSIONS}

In this work, we have demonstrated the capability of the SPCVD process to produce various complex core compositions, that is to say $\mathrm{SiO}_{2}-\mathrm{Al}_{2} \mathrm{O}_{3}-\mathrm{Yb}_{2} \mathrm{O}_{3}-\mathrm{Ce}_{2} \mathrm{O}_{3}-\mathrm{F}$ and $\mathrm{SiO}_{2}-\mathrm{Al}_{2} \mathrm{O}_{3}-\mathrm{P}_{2} \mathrm{O}_{5}-\mathrm{Yb}_{2} \mathrm{O}_{3}$. We have successfully drawn these preforms into fibers suited for moderate and high power lasers. The 11/130 AlFYbCe and AlPYb fibers have exhibited high PCE over $71 \%$ for output powers around $30 \mathrm{~W}$, with $\mathrm{M}^{2}$ parameters close to 1 . Photodarkening has been mitigated in both compositions, using a small content of cerium for the AlFYb core. The 20/130 fiber has also shown an excellent PCE of $74.5 \%$ for high powers up to $100 \mathrm{~W}$, unlike the 20/400 fiber whose measured PCE is rather low (53\%), probably due to non-optimized splicing process for these large diameter fibers. Future work focuses on synthesizing new core compositions for 20/130 and 20/400 fibers and on improving the characterizations of these fibers, but also on studying other rare earth ions.

\section{REFERENCES}

[1]: Maiman, T.H., "Stimulated optical radiation in ruby". Nature, 187, 493-494 (1960).

[2]: Carter R.M., Throughton M., Chen J., Elder I., Thomson R.R., Esser M.J.D., Lamb R.A. and Hand D.P., "Towards industrial ultrafast laser microwelding: $\mathrm{SiO}_{2}$ and BK7 to aluminum alloy". Appl. Opt. 56(16), 4873-4881 (2017).

[3]: Lefort C., "A review of biomedical multiphoton microscopy and its laser sources". J. Phys. D, 50(42), 423001423026 (2017).

[4]: Qu Z., Li Q., Meng H., Sui X., Zhang H. and Zhai X., “Application and the key technology on high power fiberoptic laser in laser weapon”. Proc. SPIE 9294, 92940C-1-92940C-5 (2014).

[5]: Poole S.B., Payne D.N. and Fermann M.E., "Fabrication of low-loss optical fibers containing rare earth ions". Electron. Lett., 21(17), 738-740 (1985).

[6]: Tünnermann A., Schreiber T., Röser F., Liem A., Höfer S., Zellmer H., Nolte S and Limpert J., "The renaissance and bright future of fibre lasers," J. Phys. B: At. Mol. Opt. Phys. 38, S681-S693 (2005).

[7]: Zervas M.N. and Codemard C.A., "High power fiber lasers: A review," IEEE J. Sel. Top. Quantum Electron. 20(5), 219-241 (2014).

[8]: Jackson S.D., "Towards high-power mid-infrared emission from a fibre laser," Nature Photon., 6, 423-431 (2012).

[9]: Barnini A., Robin T., Cadier B., Aka G., Caurant D., Gotter T., Guyon C., Pinsard E., Guitton P., Laurent A. and Montron R., "Rare earth-doped optical fiber core deposition using full vapor-phase SPCVD process". Proc. SPIE 10100, 101000D-1-101000D-10 (2017). 
[10]: Pavy D., Moisan M., Saada S., Chollet P., Leprince P. and Marrec J., "Fabrication of optical fiber preforms by a new surface-plasma CVD process," Proc. of $12^{\text {th }}$ ECOC, (Barcelona-Spain), 19-22 (1986).

[11]: Golant K.M., "Bulk silicas prepared by low pressure plasma CVD: formation of structure and point defects," in Pacchioni G., Skuja L. and Griscom D., [Defects in $\mathrm{SiO}_{2}$ and related dielectrics: Science and technology], Kluwer Academic Publishers, Printed in The Netherlands, 427-452 (2000).

[12]: Koponen J., Söderlund M., Hoffman H., Kliner D. and Koplow J., "Photodarkening measurements in large mode area fibers," Proc. SPIE 6453, 64531E-1-64531E-11 (2006).

[13]: Engholm M., Jelger P., Laurell F. and Norin L., "Improved photodarkening resistivity in ytterbium-doped fiber lasers by cerium co-doping," Opt. Lett., 34(8), 1285-1287 (2009).

[14]: Le Guerroue F., Gotter T., Le Masson R., Prades S., Ranger C., Robin T. and Cadier B., "Photodarkening in Ybdoped fibers for fiber lasers," Fiber integrated opt., 28(1), 60-64 (2009).

[15]: Jetschke S., Unger S., Schwuchow A., Leich M. and Kirchhof J., "Efficient Yb laser fibers with low photodarkening by optimization of the core composition". Opt. Express, 16(20, 15540-15545 (2008).

[16]: Manek-Hönninger I. and Boullet J, "Photodarkening and photobleaching of an ytterbium-doped silica double-clad LMA fiber”. Opt. Express, 15(4), 1606-1611 (2007).

[17]: Birkeneder F., Berg R.W. and Bjerrum N.J., "Raman and NMR studies in the system phosphoryl chloridealuminum chloride". Acta Chem. Scand., 47(4), 344-357 (1993).

[18]: Unger S., Schwuchow A., Jetschke S., Reichel V., Leich M., Scheffel A. and Kirchhof J., "Influence of aluminumphosphorus codoping on optical properties of ytterbium-doped laser fibers". Proc. SPIE 7212, 72121B-1-72121B-9 (2009).

[19]: Kirchhof J., Unger S., Schwuchow A., Jetschke S. and Knappe B., "Dopant interactions in high power laser fibers". Proc. SPIE 5723, 261-272 (2005). 